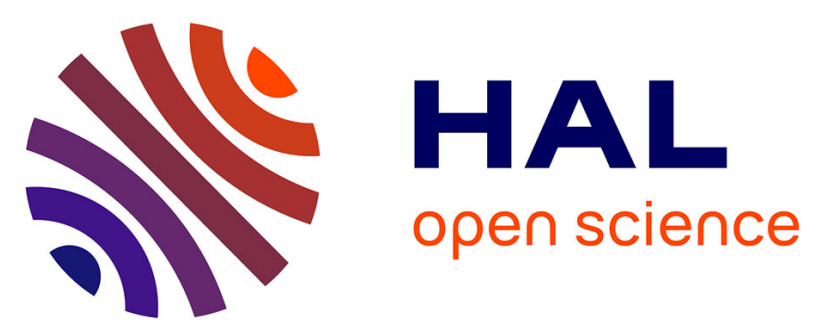

\title{
Modélisation d'un transformateur à shunts magnétiques utilisé dans l'alimentation H.T. d'un générateur micro-ondes à magnétron
}

Mohamed Chraygane, Maurice Teissier, Ahmad Jammal, Jean-Pierre Masson

\section{- To cite this version:}

Mohamed Chraygane, Maurice Teissier, Ahmad Jammal, Jean-Pierre Masson. Modélisation d'un transformateur à shunts magnétiques utilisé dans l'alimentation H.T. d'un générateur micro-ondes à magnétron. Journal de Physique III, 1994, 4 (11), pp.2329-2338. 10.1051/jp3:1994280 . jpa00249266

\section{HAL Id: jpa-00249266 https://hal.science/jpa-00249266}

Submitted on 1 Jan 1994

HAL is a multi-disciplinary open access archive for the deposit and dissemination of scientific research documents, whether they are published or not. The documents may come from teaching and research institutions in France or abroad, or from public or private research centers.
L'archive ouverte pluridisciplinaire HAL, est destinée au dépôt et à la diffusion de documents scientifiques de niveau recherche, publiés ou non, émanant des établissements d'enseignement et de recherche français ou étrangers, des laboratoires publics ou privés. 


\title{
Modélisation d'un transformateur à shunts magnétiques utilisé dans l'alimentation H.T. d'un générateur micro-ondes à magnétron
}

\author{
Mohamed Chraygane. Maurice Teissier, Ahmad Jammal et Jean-Pierre Masson \\ U.C.B.L., Laboratoire d'Electrotechnique et d'Electronique de Puissance, 43 Boulevard du \\ 11 novembre 1918, 69622 Villeurbanne Cedex
}

(Reçu le 7 octobre 1993, révisé le 5 juillet 1994, accepté le 5 août 1994)

\begin{abstract}
Résumé. - L'alimentation haute tensıon des magnétrons, utilisés comme source d'énergie microondes dans l'industrie, est de conception classique: un transformateur monophasé à fuites magnétiques alimentant une cellule doubleuse de tension et stabilisatrice de courant. Un schéma équivalent en $\pi$ du transformateur est présenté, prenant en compte la saturation des différentes parties du fer et la stabilisation du courant du magnétron. Trois inductances sont caractérisées par les relations non lınéaires entre flux et courant magnétısant. Ce modèle a été testé à l'aide du logiciel de calcul E.M.T.P. (Electro-Magnetic Transients Program), au voisinage du régime nominal. Les résultats théoriques. comparés aux mesures expérimentales, se trouvent en bon accord avec elles.
\end{abstract}

\begin{abstract}
The high voltage power supply for magnetron, used for the modular microwave generators in industrial applications, is of a classical design: a single phase leakage flux transformer supplying a cell, composed of a capacitor and a diode, which multiplies the voltage and stabilizes the current. A $\pi$ model of this transformer is developed, taking the saturation phenomena and the stabilization process of the magnetron current into account. Three inductances are characterized by the non linear relations between flux and magnetizıng current. This model was tested by E.M.T.P. software (Electro-Magnetic Transients Program), near the nominal state. The theoretical results were compared to experimental measurements with a good agreement.
\end{abstract}

\section{Introduction.}

L'alimentation haute tension des magnétrons $800 \mathrm{~W}$ à $2450 \mathrm{MHz}$, utilisés comme source d'énergie micro-ondes, est de conception classique. Elle comporte un transformateur haute tension à fuites magnétiques alimentant une cellule doubleuse de tension et stabilisatrice de courant [1-3]. Ce transformateur à shunts permet la stabilisation du courant anodique moyen du magnétron, en utilisant la saturation du circuit magnétique. les caractéristiques du magnétron [4, 5], ainsi que ses valeurs limites, imposent une conception adéquate de son alimentation. Contrairement au transformateur ordinaire, les flux de fuites dans les shunts sont 
[3] Mosharow V. E. et al., Luminescent paint for pressure distribution investigation on a model surface in the wind tunnel, CIAM Works, $\mathrm{N}^{\circ} 232$ (1988).

[4] Mosharow V. E. et al., Application of the Lumınescent Pressure Transducer in aerodynamic experiment, CIAM Works, $\mathrm{N}^{\circ} 258$ (1989).

[5] Kavandi J., Callis J., Gouterman M. Khalil G., Wright D., Green E., Burns D., McLachlan B., Luminescent Barometry in Wind Tunnels, Rev. Sci. Instrum. 61 (1990) 3340-3347.

[6] Crowder J. P., «Flow Visualization In Flight Testing » AIAA 90-1273, 5th Biannual Flight test Conference, Ontario, CA (May 22-24, 1990).

[7] Kavandi J. L., Crowder J. P., Pressure Indicatıng Paint for Aerodynamic Surface Pressure Measurements, AIAA 90-1516 (June 1990).

[8] Gouterman M., Callis J., Burns D., Kavandi J., Gallery J., Khalil G., Green E., McLachlan B., Crowder J., «Luminescence Imaging for Aerodynamic Testing », Proceedings of the ONR/NASA Workshop on Quantitative Flow Vizualization, Purdue University.

[9] Vollan A., Alati L., "A New Optical Pressure Measurement System », 14th ICIASF Congress, Rockville, MD (October 27-31, 1991).

[10] Engler R. H., Hartmann K., Schulze B., "Aerodynamic Assessment of an Optical Pressure Measurement System (OPMS) by Comparison with Conventional Pressure Measurements in High Speed Wind Tunnel », 14th ICIASF Congress, Rockville, MD (October 27-31, 1991).

[11] Morris M. J., Donovan J. F., Kegelman J. T., Schwab S. D., Levy R. L., Crites R. C., Aerodynamic Applications of Pressure-Sensitive Paint, AIAA 90-0264 (January 1992).

[12] Troyanovsky I., Sadovskii N., Kuzmin M., Mosharov V., Orlov A., Radchenko V., Fonov S., "Set of Luminescence Pressure Sensors-LIPS for Aerospace Research », 1st European conference on optical chemical sensors and biosensors, Graz, Austria (12-15 April 1992).

[13] Bukov A. P., Orlov A. A., Mosharov V. E., Pesetsky V. A., Sorokin A. V.. Phonov S. D., Alaty L., Colucci V., «Application of Luminescence Quenching for Pressure Field Measurements on the Model Surface in a Wind Tunnel », conference «Wind Tunnels and Wind Tunnel Testing Techniques », Sauth Hempton (September 1992).

[14] Crites R. C., Benne M. E., Morris M. J., Donovan J. F., « Optical Surface Pressure Measurements : Initial Experience in the MCAIR PSTWT», conference «Wind Tunnels and Wind Tunnel Testing Techniques », Sauth Hempton (September 1992).

Proofs not corrected by the authors. 


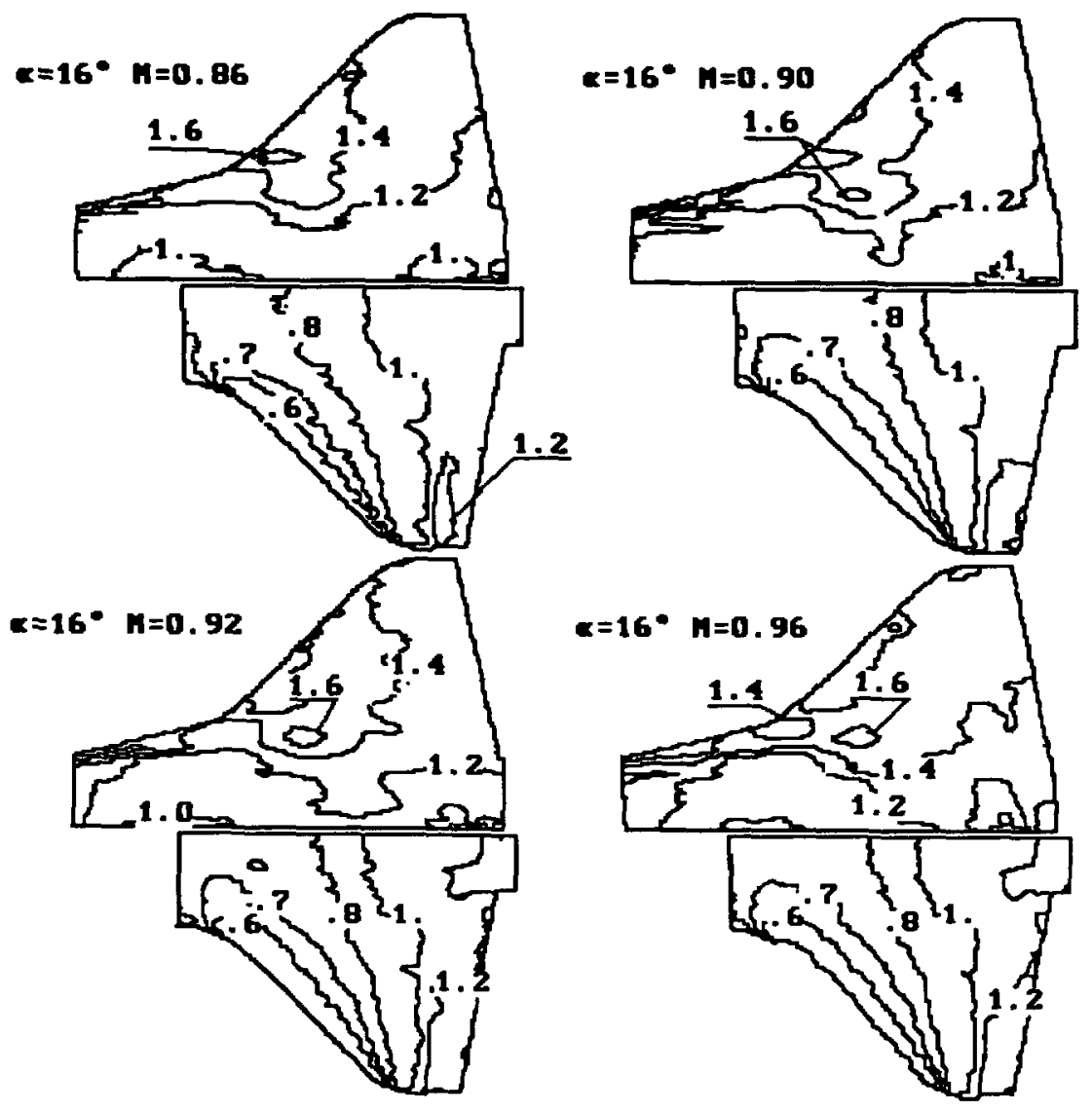

Fig. 8. - Mach number field at $\alpha=16^{\circ}$.

\section{Conclusions.}

The LPS technology proved to be a highly effective way of measuring the pressure fields on the model surface in the wind tunnel experiments. Results from this method compare favorably with those of pressure taps at $M=0.92$ and angle of attack $12^{\circ}$, except near the leading edge. That discrepancy is due to the flow dust covering the model surface. The flow particulars, revealed on the base of mach number maps on upper and down model surfaces, permit to understand the flow behavior and its influence on integral aerodynamic forces acting on the model at tested Mach number range 0.85 0.96 and angles of attack range $8^{\circ}-12^{\circ}$.

\section{References}

[1] Morris M. J., Donovan J. F. et al , Aerodynamic Application of Pressure-Sensitive Paint. AIAA 920264 (1992).

[2] Ardasheva M. M., Newsky L. B., Perwushin G. E., Pressure distribution measurement technique with an indicator paint, $J$ Appl. Marh. Tech. Phys., $N^{\circ} 4$ (1985). 
place up to flow in the tip wing section and down to flow in the root section of the wing, and the supersonic flow region slightly increases on the lower wing surface. The Mach number distribution at $12^{\circ}$ angle of attack on the upper and lower wing surfaces is presented in figure 7 .

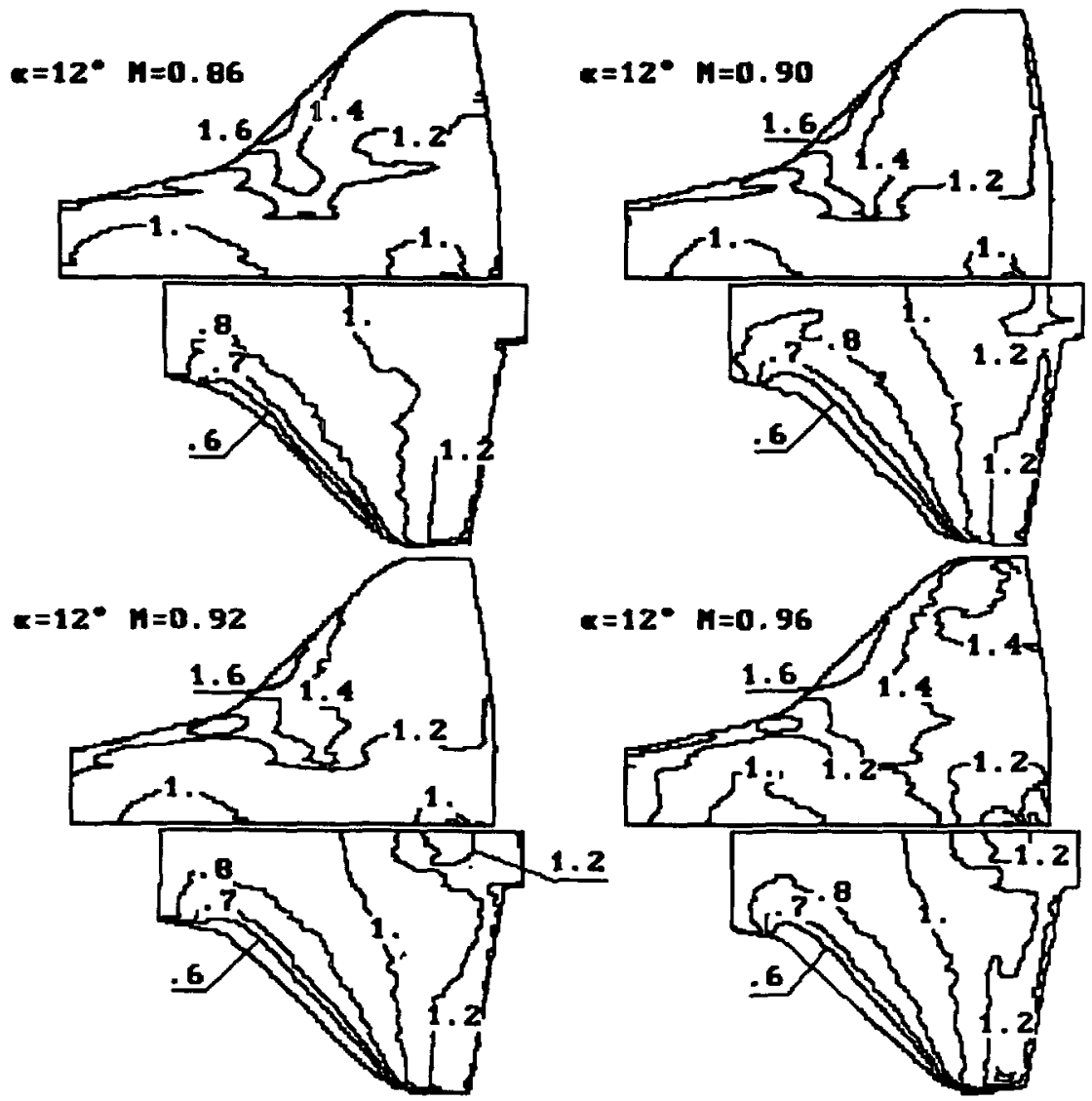

Fig. 7. - Mach number field at $\alpha=12^{\circ}$.

The shock wave displaces to the leading edge and its curvature increases in comparison with $10^{\circ}$ angle off attack. There is narrow decompression zone in the pressure distribution on root cross sections of the upper wing surface. This zone may be attributed to a vortex flow from the leading edge of the root wing section.

The Mach number increase from 0.85 to 0.96 is accompanied by shock wave displacement to the trailing edge in the root wing sections. The maximum Mach number on the upper wing surface is approximately the same as at $8^{\circ}$ and $10^{\circ}$ angle of attack (Fig. 7). The flow on the upper wing surface separates from leading edge at $14^{\circ}$ and $16^{\circ}$ angles off attack in all tested Mach number range. There is vortex from the root sections of the wing and supersonic flow zone appears (Fig. 8). On the lower wing surface the supersonic zone covers the elevons and an aft body of the model. 


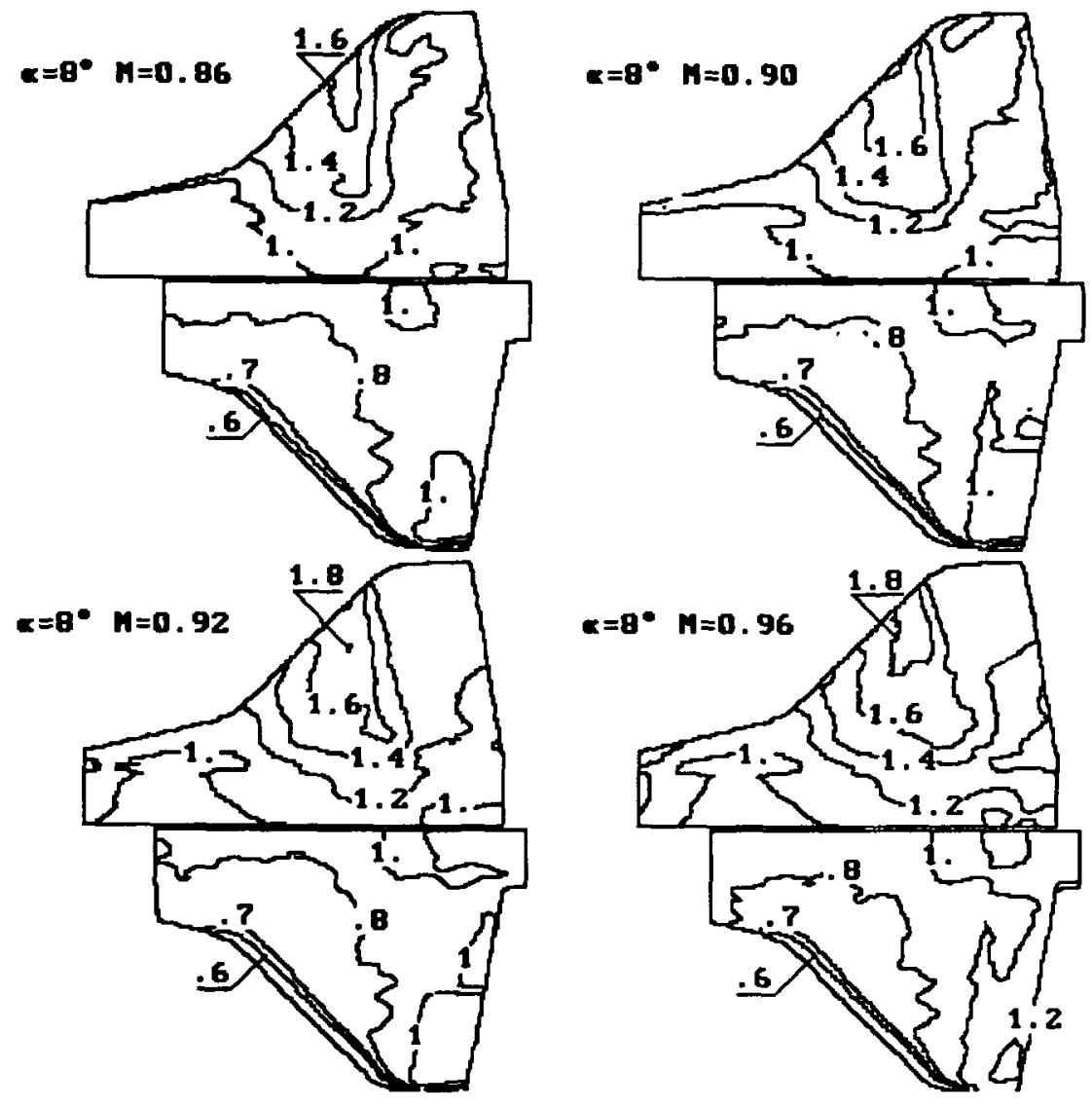

Fig. 5. - Mach number field at $\alpha=8^{\circ}$.

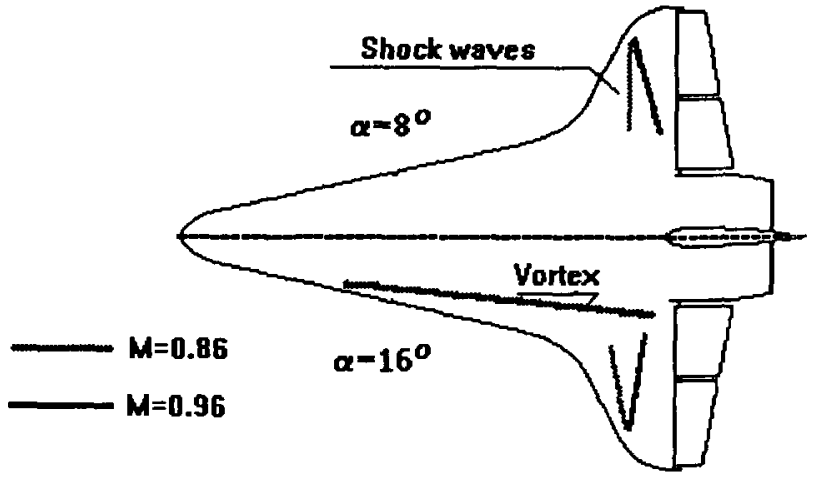

Fig. 6. - Flow Structure. 


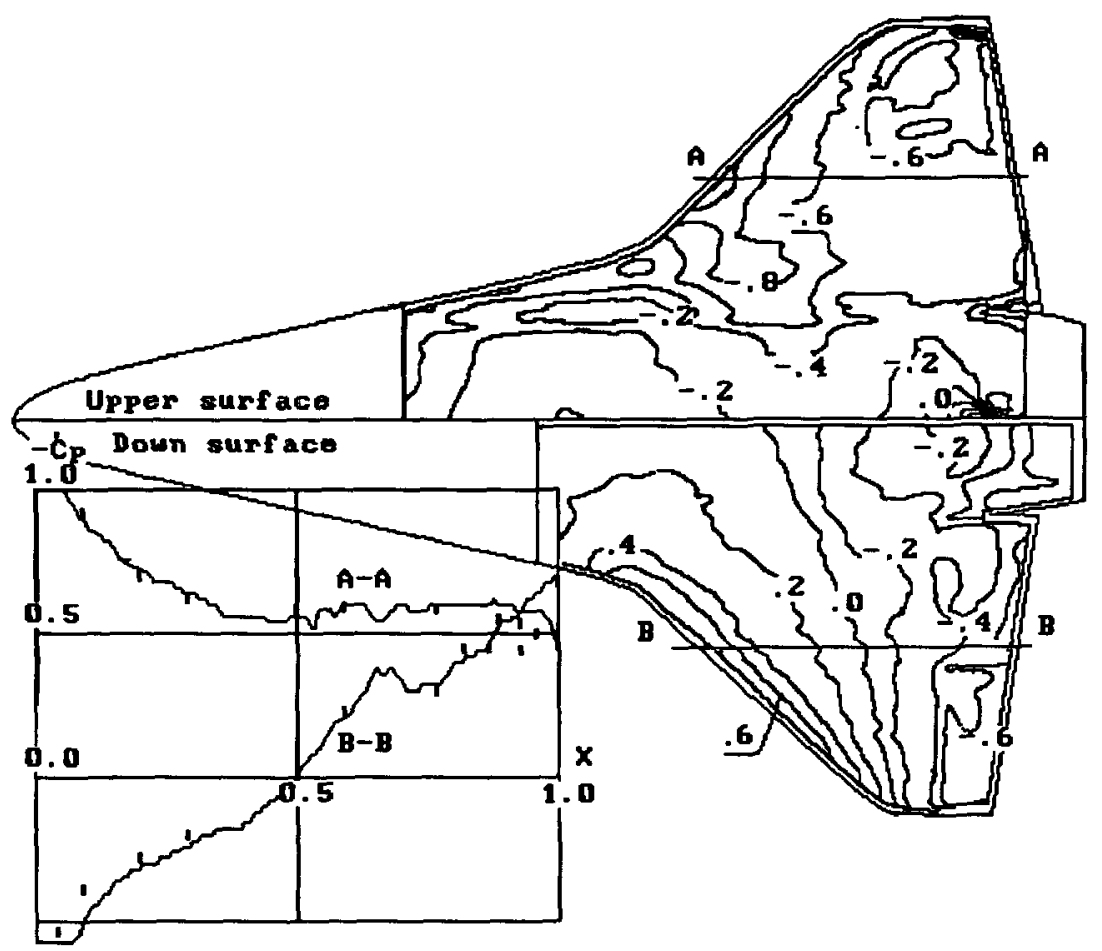

Fig. 4. - Pressure distribution on the model at $M_{\infty}=0.92$ and $\alpha=12^{\circ}$, compared with taps.

$M=0.86$ and $8^{\circ}$ angle of attack. The flow accelerates up to supersonic Mach numbers. The slanting shock wave arises in maximum profile thickness zone of the wing (Fig. 6). The pressure coefficient decreases up to $C_{p}=-1.2$ in maximum decompression zone, what corresponds local Mach number $M \approx 1.6$. The pressure on a trailing edge at this angle of attack recovers everywhere away from tip wind section. One can conclude what diffusor flow separation does not take place in trailing edge zone on upper wing surface. On the lower surface the flow decelerates near leading wing edge and accelerates again up to supersonic values at a elevon zone (Fig. 6). The Mach number increase from 0.85 to 0.96 (Figs. 5, 6) at this angle of attack leads to :

- increase of the supersonic zone on the upper wing surface ;

- shock wave displacement in the direction of the trailing edge by $8 \ldots 10 \%$ of the local wing chord at the root section of the wing, but at the tip section the shock wave does not change position ;

- flow separation behind the shock wave at $M>0.9$. Maximum decompression in supersonic zone is about $C_{\mathrm{p}}=-1.1$ at $M=0.96$ what corresponds local $M=1.85$.

The angle of attack increase from $8^{\circ}$ to $10^{\circ}$ at flow Mach number $M=0.85$ leads to:

- shock wave displacement up to flow by $4 \%$ of the local chord;

- shock wave distortion along the wing span;

- supersonic zones increase on the upper wing surface and appearance of the supersonic flow on the lower wing surface;

- shock wave appearance on the lower surface of outer elevon section. While flow Mach number grows from 0.85 to 0.96 at the $10^{\circ}$ angle of attack, shock wave displacement takes 
Pressure Sensitive Paint LPS 18L1, has being developed by TsAGI and Moscow State University and now produced by Optrod Ltd, was used to measure pressure distribution on the models. The paint has the following performances:

\begin{tabular}{|l|r|}
\hline spectrum region of absorption, $\mathrm{nm}$ & $320 \ldots 340$ \\
spectrum region of luminescence, $\mathrm{nm}$ & $450 \ldots 500$ \\
sensitivity (response), \%/bar & 65 \\
full scale range, bar & up to 5 \\
temperature range ${ }^{\circ} \mathrm{C}$ & $0 \ldots 60$ \\
pressure response time, $\mathrm{s}$ & 0.1 \\
\hline
\end{tabular}

Calibration curve for LPS L1 is presented in figure 3.

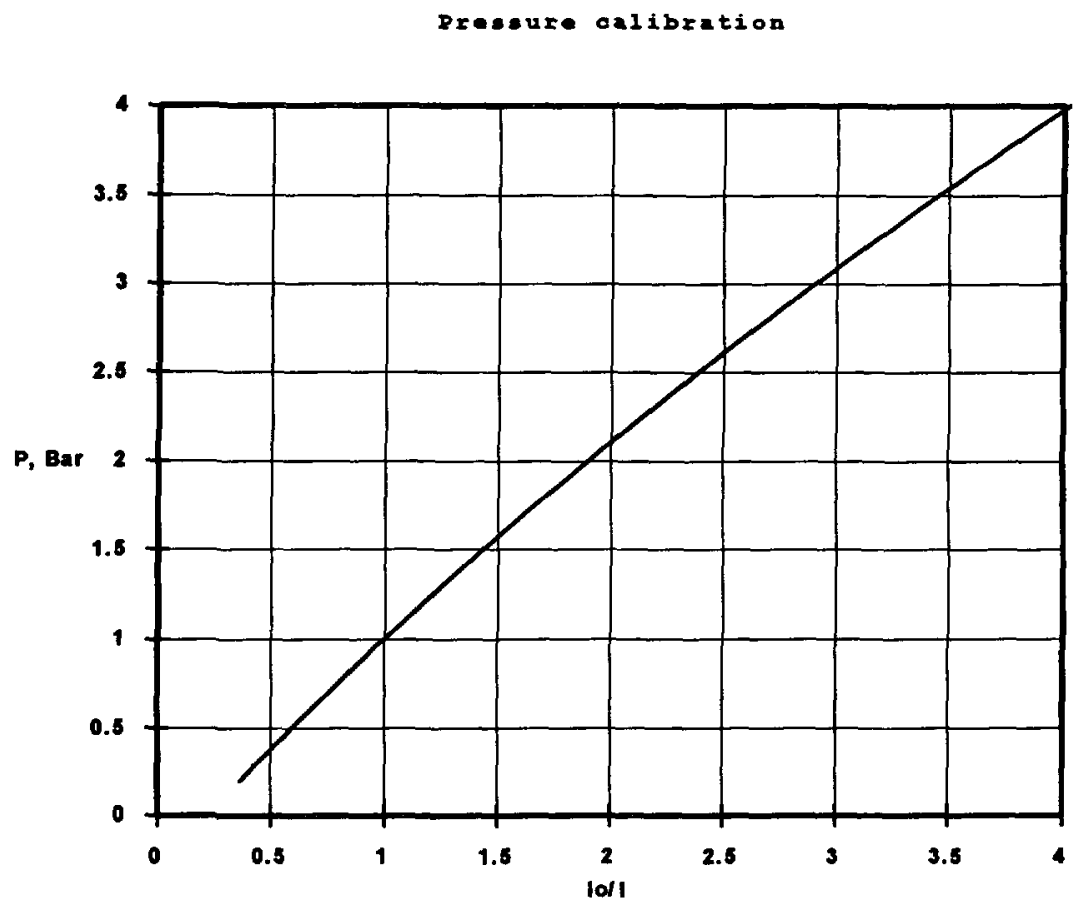

Fig. 3. - Pressure calibration curve for LPS L1.

\section{Experimental results.}

Figure 4 shows a typical comparison of LPS data with pressure tap data obtained for geometrical identical model in the T-109 wind tunnel by Blagoweshensky and Kurilov. In general, away from the leading edge, the agreement between LPS and pressure tap is good.

The experimental results are presented in figures 5, 7 and 8 as isomach lines map for upper and lower model surfaces. The Mach number maps were calculated from pressure fields in adiabatic flow approach.

The pressure and Mach number map analysis permit to make some conclusions about flow structure around upper and lower model surface. Let's consider, for example, the flow at 
authentic of the information. Preliminary amplitude calibration of the acquisition channel

$$
I(x, y, U) \cong h_{0}+h_{1} U+h_{2} U^{2}+h_{3} U^{3}
$$

$\left(h_{k}=h_{k}(\uparrow, y), k=0,1 ..\right)-$ coefficients of approximation - allows to obtain the field of relative intensities $I\left(x, y, P_{\mathrm{e}}\right) / I(x, y, P(x, y))$, for each pair of the measuring and reference frames (subscript e), and with the calibration of paint dependence $P=P\left(I_{\mathrm{e}} / I\right)$ which is supposed to be equal along the whole surface, to obtain pressure field $P(x, y)$ or pressure coefficients field $C_{\mathrm{p}}(x, y)$ on the image of the tested surface of the model. As mentioned above paint calibration is obtained in bidimensional approximation (4.1) with relative intensity normalized to intensity at some $T_{\mathrm{e}}, P_{\mathrm{e}}$. But reference image is acquired at real air pressure $P_{\mathrm{w}}$ and model temperature $T_{\mathrm{w}}$ in wind tunnel and (4.1) must be modified to the next :

$$
P\left(I_{\mathrm{r}}, I_{\mathrm{rw}}, T\right)=\sum_{i=0}^{M} \sum_{j=0}^{N} \chi_{i}, I_{\mathrm{rw}}^{\prime} I_{\mathrm{r}}^{\prime} T^{J},
$$

there $I_{r w}$ is a root of equation :

$$
P_{\mathrm{w}}\left(I_{\mathrm{rw}}, T\right)=\sum_{I=0}^{1} \sum_{l=0}^{N} \chi_{i j} I_{\mathrm{rw}}^{\prime} T_{\mathrm{w}}^{\prime} .
$$

The outcome image requires as a rule an additional filtration to suppress noise and to outline the contour of the model.

\section{Model and test program description.}

The measurements of pressure distribution on a $0.833 \%$ « Buran " model were made in the TsAGI T-112 wind tunnel. A model scheme is presented in figure 2 . The model was tested at Mach numbers $0.85,0.86,0.87 .0 .88,0.89,0.9,0.92,0.94,0.96$ and angles of attack $8^{\circ}, 10^{\circ}$, $12^{\circ}, 14^{\circ}$ and $16^{\circ}$.
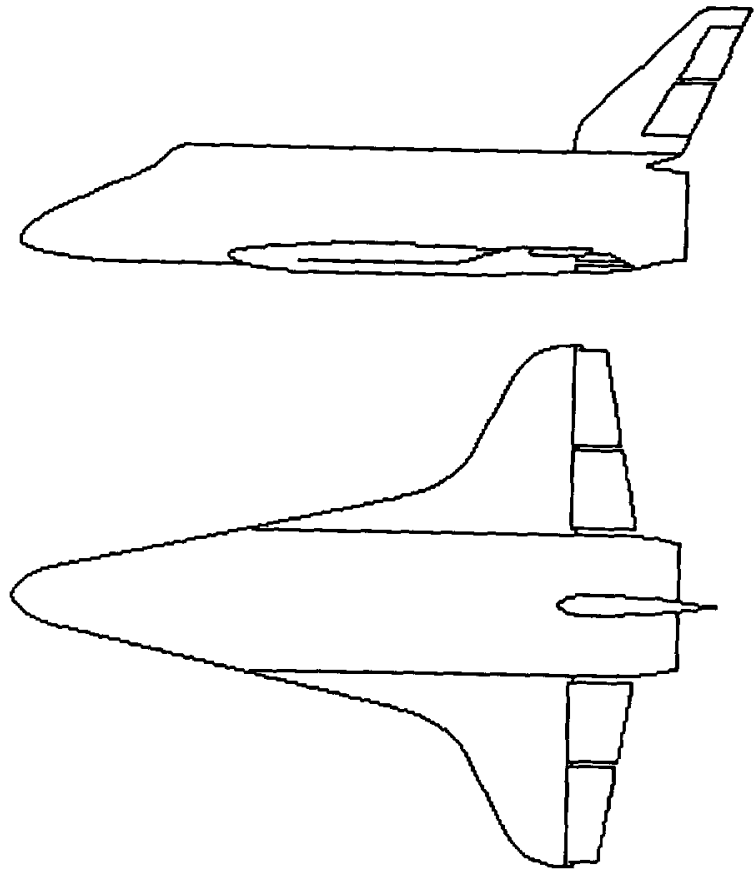

Fig. 2. - Model geometry. 


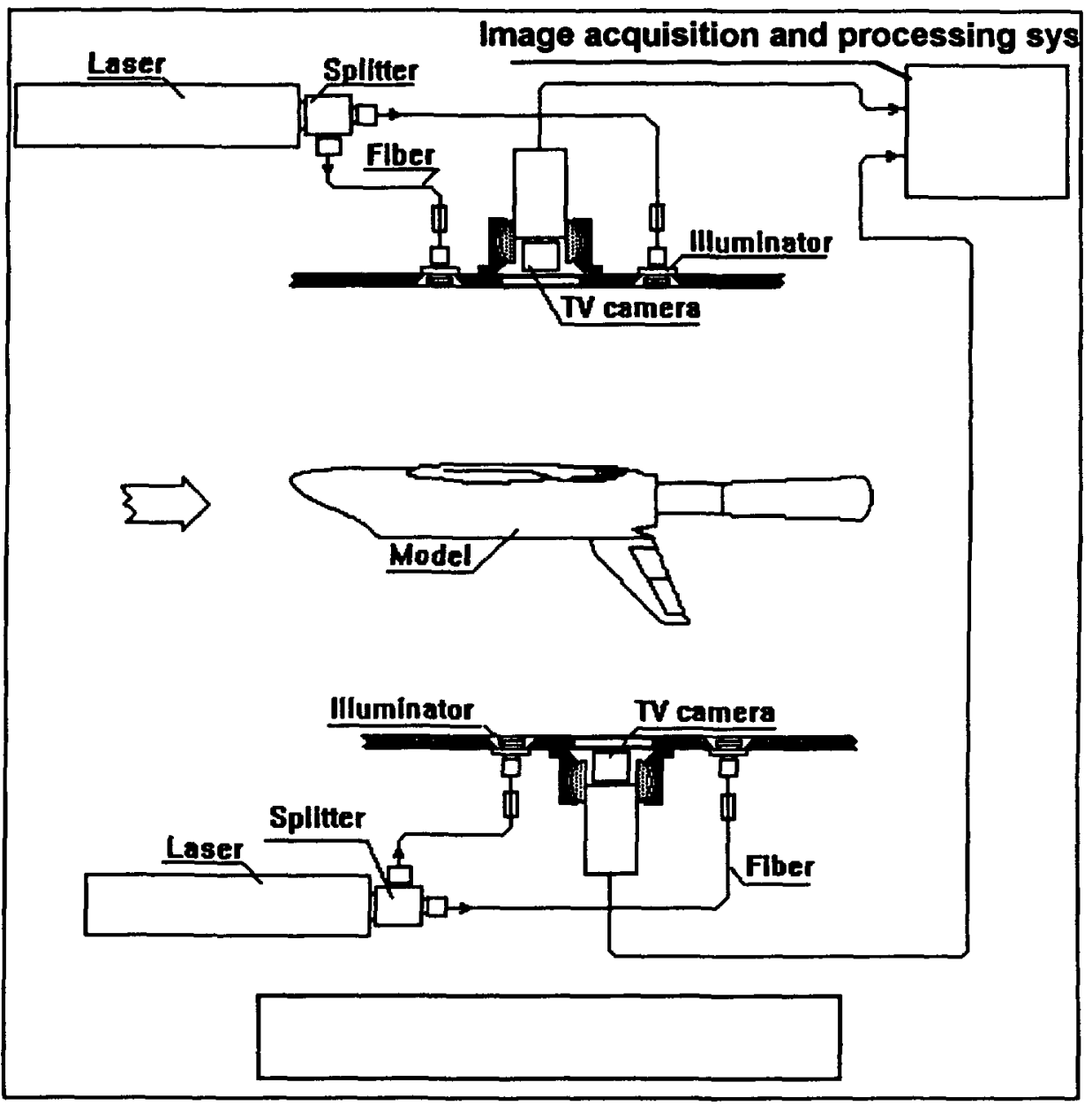

Fig. 1. - Illumination and detection system.

where $\chi_{\| \prime}-$ approximation coefficients, L, $\mathbf{J}$ - power of approximation polynomial, and usually $M=2$, and $N=3, I_{\mathrm{e}}$ is measured usually at $P=1 \mathrm{bar}$, and $T=20^{\circ} \mathrm{C}$.

4.2 Technique of INFORMation ACQUisition AND PROCESSING. - Before running the wind tunnel the so-called reference frame is registered for every angular position of the model, either on the video recorder or directly in digital image acquisition system. The reference frame bears information about luminescence distribution $U\left(I\left(x, y, P_{\mathrm{e}}\right)\right)$ with the known pressure $P_{\mathrm{e}^{*}}(U(x, y, I)$ is the amplitude characteristic of the acquisition channel, and $(x, y)-$ coordinates in the acquisition plane - image plane). To suppress the noise of video signal and acquisition channel they make averaging by 40 succeeding television frames. Thus time of averaging is $1.6 \mathrm{~s}$ and signal to noise ratio increases by $16 \mathrm{~dB}$. When the flow is at the given mode they register the measuring frame which bears information about luminescence field $U(I(x, y, P(x, y)))$, which depend on the pressure field $P(x, y)$. When the wind tunnel is cut off they register the second reference frame, which allow to evaluate the changes of paint parameters and acquisition system during the experiment and in some cases to increase 
Functions $c_{0}(T), c_{1}(T), c_{2}(T)$ must be obtained by LPS calibration. In the same manner the inverse function $P=P\left(I_{\mathrm{r}}, T\right)$ can be approximated :

$$
P\left(I_{\mathrm{r}}, T\right) \cong a_{0}(T)+a_{1}(T) I_{\mathrm{r}}+a_{2}(T) I_{\mathrm{r}}^{2},
$$

where $a_{0}, a_{1}, a_{2}$ are obtained by LPS calibration.

\section{LPS structure.}

LPS consists of four polymeric layers, which are applied consecutively to the model surface. These layers are : screen layer, first adhesive layer, second adhesive layer, active layer. The Screen Layer is composed of white paint which creates an optical uniformity on the surface of the model and increases the reflection of light. This layer also creates a chemical and physical separation between the model and the Active Layer so as the nature of the model does not influence the properties of LPS. The Adhesive Layers are applied to assure adhesion of the Active Layer to the model surface. The Active Layer consists mainly of two compounds; one being polymer which is highly permeable to oxygen and other being a luminophore which is dispersed within the polymer.

\section{The illumination and detection systems.}

The illumination system is used for active layer excitation on the total surface under study. The illumination system consists of a light source - impulse, up to $1 \mathrm{kHz}$ repetition rate, nitrogen laser with average power $100 \mathrm{~mW}$ at $\lambda=337 \mathrm{~nm}$, optical fibers for the transition of the exciting light to the test section of the wind tunnel and illuminators installed on the test section roof and floor. Signals from image detector (Intensified CCD TV-camera) are collected by the digital image acquisition system, having spatial resolution $512 \times 512$ pixels and amplitude resolution 256 grey levels. Reconstruction and presentation of pressure fields are made in the standard image processing system. The general layout of systems setup in T-112 wind tunnel is presented in figure 1.

\section{Methodology of LPS pressure measurements.}

Procedure of pressure measurement with aid of LPS consists of the following basic operation :

- coating the model with LPS ;

- LPS calibration procedure ;

- installation and ajustment of illumination system and TV-camera(s) in the wind tunnel ;

- intensity calibration of TV-camera(s) ;

- recording of luminescence intensity fields of LPS on the surface of the model at the testing parameters of airflow :

- recording of reference luminescence intensity fields of LPS on the surface of the model without airflow at known pressure level (the model remaining in same position, the same set of angles of attack);

- digital pressure field reconstruction and presentation.

4. 1 LPS CALIBRATION. - The sample for LPS calibrating is prepared simultaneously with the model. During calibration procedure one obtain the coefficients $a_{0}(T), a_{1}(T), a_{2}(T)$ of calibration curves at temperatures $T$. To use these calibrations for pressure field reconstruction bidimensional approximation is applied:

$$
P\left(I_{\mathrm{r}}, T\right)=\sum_{i=0}^{M} \sum_{i=1}^{N} \chi_{11} I_{\mathrm{r}}^{\prime} T^{\prime}
$$


influence of such effects on integral aircraft characteristics. The classic taps measurements of pressure distribution are very complex and expensive due to model itself and pressure measurement techniques. That is why the pressure taps measurements cannot be widely used as aircraft project instrument. A Luminescence Pressure Sensor (LPS) Technology, based on well-known phenomenon of oxygen quenching, permits to solve this problem. Peterson and Fitzgerald were the first using the photoluminescent quenching for flow visualization [1]. The first application for pressure field measurements was done by Nevsky and Pervushin [2] in TsAGI at the beginning of the eighties. Now LPS method is widely used by TsAGI, McDonnell Douglas Corporation, Boeing Company, NASA [3, 14]. The LPS method allows to obtain the pressure distribution practically on the total surface of the standard models, for example, on the model for balance experiments and to make experiments in parallel with another testing.

\section{Physical principles.}

The pressure measurement technique by Lur.ınescence Pressure Sensor (LPS) technology is based on deactivation of photo-excited molecules by oxygen contained in the air. The model surface is covered by a thin (thickness about $5 \div 100 \mu$ ) polymer layer containing luminophore molecules and penetrable for oxygen. Exited luminophore molecules can lost energy by light radiation luminescence, or by transfer this energy to oxygen molecules without light radiation. The part of energy lost by non radiation deactivation (luminescence quenching) is proportional to oxygen concentration in the polymer layer and oxygen mobility. According to Henry s law concentration of oxygen in polymer layer is proportional to oxygen partial pressure on its outer boundary. As consequence, luminescence output is inversely proportional to oxygen partial pressure above polymer surface and, if the partial pressure of oxygen in the air is proportional to air pressure, the effect of luminescence quenching can be used for measurement of air pressure. A quantum output $\phi(P)$ of luminescence as a function of air pressure $P$ can be described as :

$$
\phi_{0} \phi \cong 1+b_{1} P+b_{2} P^{2},
$$

where $\phi_{0}$ is the luminescence quantum output in the absence of quencher and $b_{1}$ and $b_{2}$ are parameters of the pair luminophore-quencher and polymer. These constants are temperature dependent and can be obtained by pressure and temperature calibration. The luminescence intensity distribution $I(R, P, T)$ depends on the quantum output as :

$$
I(\mathbf{R}, P, T) \cong I_{\mathrm{ex}}(\mathbf{R})\left[1-10^{-+(\mathbf{R}) n(\mathbf{R}) \ell(\mathbf{R})}\right] \phi(P, T) .
$$

Where $l_{\mathrm{ex}}(R)$ is the intensity of exciting light, $\varepsilon(\mathbf{R})$ is extinction coefficient of luminophore, $n(\mathbf{R})$ is concentration of luminophore in the polymer and $\ell(R)$ is the thickness of the polymer at a point with radius-vector $\mathbf{R}$ on the surface of the model. If the intensity measured at known environmental pressure $P_{\mathrm{e}}$ and temperature $T_{\mathrm{e}}$ (at wind-off condition) is $I_{\mathrm{e}}(\mathbf{R})=I\left(P_{\mathrm{e}}\right.$, $\left.T_{\mathrm{e}}, \mathbf{R}\right)$ and geometry of the system remains the same during the experiment, then :

$$
\begin{aligned}
& I_{\mathrm{e}}(\mathbf{R}) / I(P, T, \mathbf{R})= \\
& \quad=\left[\phi_{0}\left(T_{\mathrm{e}}\right) / \phi_{0}(T)\right]\left[1+b_{1}(T) P+b_{1}(T) P^{2}\right] /\left[1+b_{1}\left(T_{\mathrm{e}}\right) P_{\mathrm{e}}+b_{2}(T) P_{\mathrm{e}}^{2}\right] .
\end{aligned}
$$

Observing equation (1.3) there are only two unknown parameters $P$ and $T$, so this equation can be rewritten for relative intensity $I_{\mathrm{r}}$ as :

$$
I_{\mathrm{r}}=I\left(P_{\mathrm{e}}, T_{\mathrm{e}}\right) / I(P, T)=c_{0}(T)+c_{1}(T) P+c_{2}(T) P^{2}
$$

